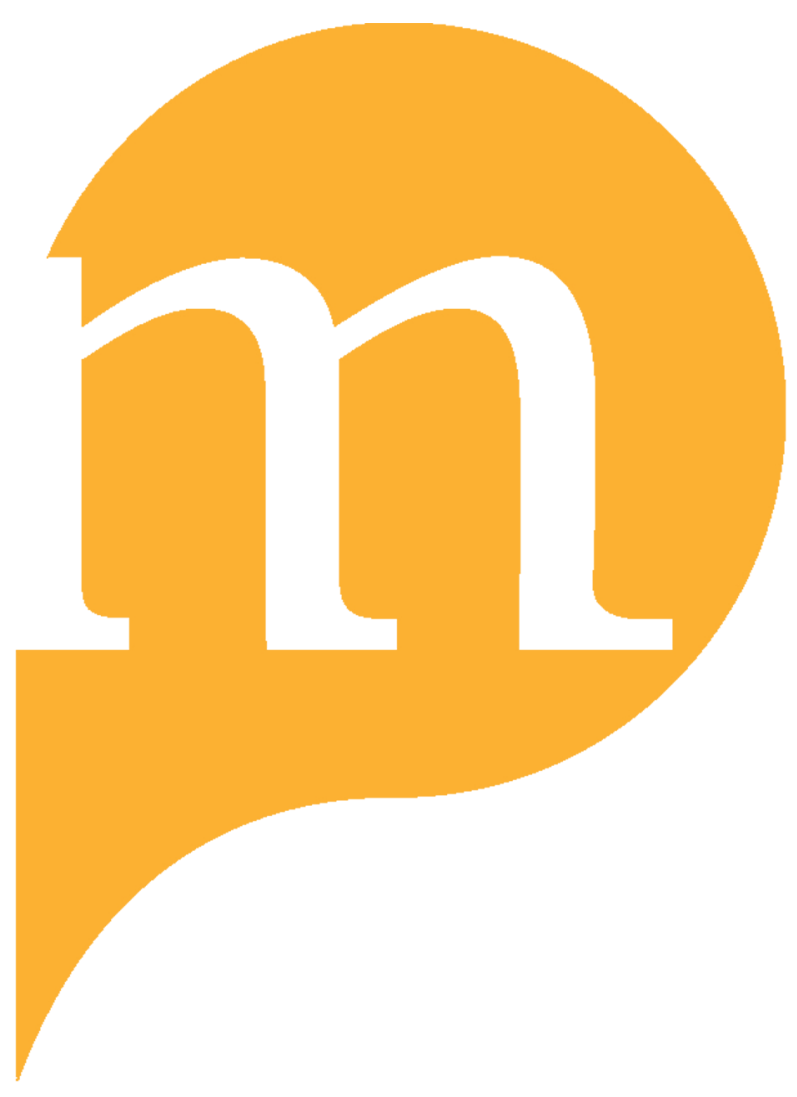

PROJECT MUSE 


\title{
The Importance of How: Directing Shakespeare with Michael Chekhov's Technique
}

\author{
TOM CORNFORD
}

University of York

"What' is important, but 'how' is much more important.'

Michael Chekhov (cited in Hurst du Prey 1977, 191)

$\mathcal{M}$

ichael Chekhov was an actor, director, teacher and philosopher of the theatre. He trained with Stanislavsky before developing his own studio in Moscow and rising to become Artistic Director of the Second Moscow Art Theatre. Political disagreements forced him to leave Russia in 1928. After a period of moving around Europe and America, he created the Chekhov Theatre Studio, first at Dartington Hall, south Devon (1936-1938) and then in Ridgefield, Connecticut (1939-1942). When war forced the Studio to close, Chekhov went to Hollywood, where he taught and acted until his death in 1955. His was a life devoted to the practice and evolution of an artistic technique for the theatre.

I first encountered Chekhov's technique in 2002 in a workshop at Shakespeare's Globe led by the actor Michael Gould, who had been playing Edmund in the Globe's 2001 production of King Lear. While playing Edmund, Michael had been struck by a distinction made by Chekhov in his book To The Actor:

I don't think it is erroneous to say that two different conceptions exist among actors concerning the stage $[\ldots]$ To some of them, it is nothing but an empty space which from time to time is filled with actors, stagehands, settings and properties; to them, all that appears on the stage is only the visible and the audible. To the others, the small space of the stage 
is an entire world permeated with an atmosphere so strong, so magnetic that they can hardly bear to part with it. (Chekhov 2002, 47)

Chekhov rejected the materialism of the former group and advocated an approach to performance that embraced the intangible:

We lay great stress in our method upon the so-called intangible means of expression $[\ldots]$ for instance, the atmosphere $[\ldots$ which is $]$ absolutely intangible but strong, often much stronger than the lines the author gives us. (Chekhov and Powers, Disc 4)

Michael Gould used his workshop to address atmosphere, beginning by reading aloud the following extract:

The actors who possess [ ... ] a love and understanding for atmosphere in a performance know [...] what a strong bond it creates between them and the spectator. Being enveloped by it too, the spectator himself begins to "act" along with the actors [ ... ] If the actors, director, author, set designer $[\ldots]$ have truly created the atmosphere for the performance, the spectator will not be able to remain aloof but will respond with inspiring waves of love and confidence. (Chekhov 2002, 48)

We laughed: obviously it couldn't be so easy, but as we worked on the atmosphere at the beginning of Hamlet, I quickly recognized the feeling of a performance going well, of jointly achieving a creative state. A hitherto elusive condition was suddenly accessible through simple, practical means. This was, for Chekhov, the only purpose of technique: 'to invoke our inspiration and get into a creative state $[\ldots]$ by our own will' (Chekhov and Powers, Disc 4). The value of such a technique became increasingly apparent as I started to direct and to teach acting, and I began to use and teach it gradually, dropping other approaches or re-framing them in dialogue with the principles articulated by Chekhov.

My earlier training had fallen mainly into two areas: verbal and psychological. The verbal approach is based on the assumption that the text contains codified authorial instructions so that, for instance: "Shakespeare tells an actor quite clearly when to go fast, when to go slow, when to pause, when to come in on cue" (Hall 41). Its determinism is authorized by particular ways of reading and speaking which are valorized as somehow authentic (to the nature of dramatic verse, to the practices of the early modern playhouse, or to Shakespeare himself). Practitioners of this approach vary from Peter Hall's prescriptive insistence upon "the sanctity of the line" (Hall 50) to Cicely Berry's more open, inclusive preference for 
"a real physical involvement with the language" (Berry 14). All, however, share an emphasis on text both as the principal guide to rehearsal and the primary means of communication in performance.

The prioritizing of speech has a tendency to generate talking-head performances in which non-verbal communication is minimal or deployed mainly to illuminate elusive meanings. Recent historiographical and textual scholarship on actors' parts has also given us historical reasons to suspect that this apparent fidelity to Shakespeare's text may be no such thing and may indeed rob us of a layered and contested verbal space constructed by multiple texts containing cues that are often repeated to create complex interactions, rather than the simple linearity of a single script. ${ }^{1}$ What is more, the early modern theatre generated a diverse range of other kinds of performance-texts: extemporized speech, song, dance, fencing and other physical performances for which a primarily verbal approach offers the director no vocabulary. Such an approach also inevitably prioritizes those characters (invariably male and usually upper-class) who speak most and are therefore made to seem more significant-even more alive-than other roles. To me this seems both politically insupportable and theatrically undesirable, as does the verbal approach's tendency towards authoritarianism: if the text is given unequivocal authority, then the director (in teaching actors both to read and speak it) is the power behind its throne.

I therefore knew that I had to find a language for rehearsal that would enable me to work with each actor's body-mind, and would offer them freedom within the context of an interdependent ensemble whose interpretative decisions could be jointly evolved. The predominant model for such an approach is broadly Stanislavskian. It scores action as a series of units guided by characters' objectives and is predicated upon an interpretation of their inner life.

This psychological approach is, however, frequently based upon a misunderstanding of Stanislavsky's system that "supposes that all onstage action is motivated exclusively by psychological intention" (Bogart and Landau 16) and scholars have frequently observed the pitfalls of grafting a predominantly Freudian conception of the human subject onto an early modern play-text. Rather than presenting a plausible psychological through-line, Shakespeare's plays often unfold through a series of discontinuities, with characters playing different roles in different scenes. In order to portray that, actors must be capable of treating characters as a series of images to be embodied, rather than a single psychological narrative. The psychological approach is poorly equipped to do this, since it 
tends to ask the actor to identify with the character rather than to stand outside of it and acknowledge its otherness.

Chekhov's technique, however, which depends continually upon a dialogue between what he called "imagination and incorporation" (Chekhov 2002, 21-34), is ideally equipped to enhance productive discontinuities of character:

The actor imagines with his body $[\ldots]$. The more developed and stronger the image, the more it stimulates the actor to physically incorporate it with his body and voice. On this natural ability of the actor we base our principle of Incorporation [ ... ]. The first step [the actor] must take is to imagine, as it were another body for himself [ . . . But he must imagine this within his real, visible body, occupying the same space. (Chekhov and Gordon 95-100)

Rather than grounding his characterization in the day-to-day experience of continuous selfhood (that authorizes a psychological interpretation of his role), Chekhov's approach locates the truth of the actor's performance in a series of images. That process liberates the actor from contemporary pseudo-naturalism because his performance does not need to cohere into a single narrative, and can thus explore genres other than the realistic and cultural contexts other than the lived present.

I am often struck, for instance, by the contrast between the fastidious details observed by designers and makers of clothing for Original Practices productions and the relative lack of attention paid to the interaction between the clothes they make and the bodies of the actors for which they are made. By contrast, Chekhov's process of imagining another body for the character offers the actor an opportunity to consider, for instance, the psychophysical effect of a ruff which radically separates head from trunk (embodying Cartesian dualism, perhaps) or of a fully-fastened doublet around the chest. Doublets are commonly worn open as though they were leather jackets which belong, in terms of acting, to twentieth century American realism and its emphasis on the free expression of personal feelings: the wearers' hearts spill out of them. Thus, by wearing the clothes but ignoring the cultural practices, period drama is reduced to fancy dress. Chekhov's imaginary body enables an actor to take the opposite approach and to explore the psychophysical consciousness of historical characters through analysis, understanding and embodiment of their material culture.

This technique can also be used to explore each character in the aesthetic context of a particular play. Rather than settling, as the psychologi- 
cal approach does, for realism as a default genre, it can find a psychophysical vocabulary for style. Working on Cymbeline with a group of actors from a wide range of cultures drew my attention to this problem from the edited text's first moment: "Enter Queen [Spanish], Posthumus [Korean] and Imogen [Canadian]" (SD at head of 1.2). ${ }^{2}$ As each actor strived for their particular notion of truth, the effect was of three productions forced to share one stage. My solution was to pool our cultural resources and find a style that spoke to the company's shared sense of the play by building a vocabulary of images gathered and created by the actors. This vocabulary gave form to the stylistic elements of the play that we chose to stress: its fairy-tale narrative, archetypal and theatrical characters and its volatility. Since the project was not a full production, the visual realization of this aesthetic was not developed, but it was nonetheless present in the exaggerated, line-drawn quality of the characterizations and the deliberate theatricality of the performances.

Chekhov was insistent that, as he told his students, "style, like blood, must run through you" (Hurst du Prey 1977, 1146) and that it could not be approximated to a conventional genre:

Each play must have a special world around and about it. Hamlet is a special world. Faust is another world. We must develop each play as a world; therefore, we need a special study for each play. (Hurst du Prey 1977, 125)

The need to create a particular approach for every play has important implications for the use of Chekhov's technique in rehearsals. Although it is systematic in the sense that the technique comprises inter-related principles, concepts and exercises, it is also intentionally open-ended and flexible, and exercises derived from the Chekhovian system are not intended to be followed in a linear fashion like a recipe. Instead, Chekhov's recorded exercises exemplify certain key principles (for example that acting is always psychophysical $)^{3}$ and are intended to provide the basis for improvisation and adaptation. I therefore don't follow set patterns or routines in rehearsal but use and adapt exercises as the situation requires, always bearing in mind that technique is an enabling constraint through which we pass in order to reach a deeper freedom than we could achieve without it.

An important guide to this process is Chekhov's idea of the 'Four Brothers', which he said any work of art must possess: the senses of form, ease, beauty and wholeness (Chekhov and Gordon xxviii). The following account uses each of these, in turn, to describe my use of Chekhov's method to rehearse Shakespeare, drawing examples from projects directed 
by me for Globe Education at Shakespeare's Globe in 2011 and 2012: Hamlet and King Lear created with MA students from the Royal Conservatoire of Scotland and Cymbeline with MA/MFA students from the East 15 Acting School.

\section{The Feeling of Wholeness}

For Chekhov, it was essential that any artistic creation have an aesthetic wholeness, expressed by its "guiding idea." ${ }^{4} \mathrm{He}$ articulated the guiding idea of King Lear, for instance, as: "the value of things changes in the light of the spiritual or in the dark of the material" (Chekhov 2002, 99). Although it can be expressed by such an idea, for me, the feeling of wholeness is experienced before I can give it intellectual articulation. It is a feeling of rhythm, balance and interconnectedness (or of intentional interruptions, imbalances and fractures) between the play's constituent parts. Chekhov often spoke of the play's guiding idea as its "spine" (Chekhov and Hurst du Prey 2000, 43), and I begin work on finding this spine by asking questions about the play as a whole, which are guided by Chekhov's principles of composition.

There are two basic compositional principles in Chekhov's technique: polarity and triplicity. Polarity means any opposition of forces that are mutually antagonistic but also inseparably connected to each other. A spine is, of course, an embodiment of polarity, stretching in two directions simultaneously, as are the images of the "light of the spiritual" and "dark of the material" that defined, for Chekhov, the polarity of King Lear. ${ }^{5}$ Chekhov also insists that, in any play, "the beginning and the end are, or should be, polar in principle" (Chekhov 2002, 94). In the case of Lear, he locates this opposition in the play's central figure who is, for him, two Lears: "one [ . . ] an empty, spiritless body, the other [ . . ] a bodiless spirit" (Chekhov 2002, 104).

Working with polarity is not, however, simply a question of spotting antithetical ideas and characters; it runs much deeper in Shakespeare's writing. When Cloten says of Imogen that "I love and hate her" (Cymbeline, 3.5.70), the phrase captures the force of the polarity of love and hatred that runs throughout the play. When he encounters this line, the actor playing Cloten must have a psychophysical vocabulary for expressing its polarity in his performance so that he does not merely refer to the idea in his speech. Ana Turos (the actress cast as Cloten) and I found the necessary vocabulary in Chekhov's exercise of expansion and contraction (which I use as a daily warm-up). Beginning from a closed, crouching/ hugging position, each actor expands from a center in the chest until her 
body is in a star shape and then contracts back to the closed position. This exercise gave Ana the embodied and imaginative experience of polarity to ground her playing of the extremes of love and hatred in Cloten's relationship to Imogen. Establishing such connections between embodied experiences and abstract concepts is vital to the success of rehearsal, which depends upon giving living form to texts, concepts, intuitions and ideas.

Movement exercises also introduce the principle of triplicity, which is simply that everything (from whole plays to simple body-movements) has three phases: an opening, a development or transition, and a conclusion. In Cymbeline, we agreed that the opening section would include the separation of Imogen and Posthumus, the tricks and deceits of the Queen and Iachimo and the diplomatic tensions between Britain and Rome. The second phase was characterized by Posthumus's and Cloten's vengeful rage, Imogen's near-death, the killing of Cloten and the decisive battle. The last part comprised the play's cascade of revelations and the achievement of a peaceful resolution. This exercise focused our attention on significant motifs and movements: deceit, confusion and isolation lead to violence and chaos, which is resolved - by a series of revelations-into harmony. Therefore, in defining the play's triplicate structure, we had also defined its guiding polarity of discord and harmony.

In the context of this analysis of the play's over-arching polarity, we saw Cloten's decision to hate Imogen as a resolution to embrace violence in order to resolve confusion, and whereas it might be considered unduly providential to argue that the character must therefore perish in the play's violent middle third, as he does, it is nonetheless a helpful illustration that characters exist both independently and as compositional elements within a greater whole. This introduces the paradox (and polarity) of the individual working within the ensemble, a notion easier to grasp in practice than to articulate in theory, but essential to the development of a wholeness that contains complexity.

I begin the process of developing complexity by converting the analysis of a play's triplicity into a score of "atmospheres," I use atmospheres as the basis for the score of a performance because they can define both a shared space and the moods of distinct individuals within that space, as in the following example from Chekhov:

Imagine a disaster in the street-someone has been run over by a car. We are coming through the street and at once we come into this atmosphere $[\ldots]$ the atmosphere is living as if in the air as an independent power [ ... W When we enter into this atmosphere of disaster, we will be astonished at what we see. The injured person has a very strong mood, the 
policeman has another mood, and the audience has other moods. You will never find the person who exemplifies the whole atmosphere [ ... ] This very objective thing we call atmosphere, and in a person we call it a mood. You are going through the street, and you ask, "What has happened?", because the atmosphere came over you and filled your soul, and [...] you begin to speak, to work, to imagine, under the inspiration of this atmosphere. (Chekhov and Hurst du Prey 2000, 68-69)

In Cymbeline, we began with the narrative's progression through atmospheres of confusion, violence and revelation. Dividing the cast into three, I asked each group to give a tangible form to one of these intangible atmospheres, describing it as a color or movement or tactile quality. ${ }^{6}$ The first (confusion), was dark grey-blue and foggy, with the feeling that a storm was imminent. The second (violence and chaos) was blood-red in color and violent, with sudden explosions. The last (harmony) had a feeling of a storm having passed: the air was golden and expanding with periodic bursts of light.

I use extended improvisations to explore these atmospheres, beginning with a large rectangular space containing three smaller areas of equal size. Each of these smaller areas contains one of the atmospheres, which I ask the actors to create and explore together, while I interact with the exercise through side-coaching. ${ }^{7} \mathrm{My}$ first aim is to encourage the actors to find relationships between atmosphere and action (such as Chekhov describes around the accident in the street). My rehearsal and production notes from Cymbeline record that the main response to the atmosphere of confusion was to keep distance. Consequently, the improvisation had no impetus until I introduced a figure searching for someone (Cymbeline for Posthumus), which made the improvisation much more active. I developed it by introducing Imogen figures trying to protect Posthumus figures and then a Queen, exploiting the confusion to manipulate and disorientate the other characters.

I also ask the actors to use this exercise to explore transitions between atmospheres and the ways in which they can relate to each other across the boundaries that separate them. This helps us to develop an understanding of the movement and interaction of atmospheres through the play. It also offers an opportunity to practice crucial moments in a condensed form. I first saw Posthumus's response to receiving the "bloody cloth" (5.1.1) that apparently confirms Imogen's death, for instance, when the actor moved, during this exercise, from the atmosphere of violence to that of revelation. 
I use these improvisations repeatedly in rehearsal to give physical form to the ideas of a play, and to their interaction within its composition; but it is essential to begin from the whole and not with a separate analysis of its parts. To give student-directors an image of this process, I use the decidedly un-Chekhovian metaphor of stripping and repairing an engine. Complexity is an unavoidable part of that process as each component is taken apart, cleaned up and checked over, but it is a sense of the whole-the simplicity that contains complexity-that is crucial both for an efficient process and a thoroughly successful outcome. Without it, time is wasted, chains of cause and effect are overlooked or misdiagnosed, or, worst of all, one is faced with a performance that resembles scattered parts piled on the floor. They may all be functional, but until they are working together, they are only of interest to the aficionado who can imagine them reassembled.

\section{The Feeling of Form}

Once we have begun to develop a sense of the whole composition of the play, we have already begun to develop a feeling for its form. Chekhov told his students that, "Everything must have a form for us-inner or outer actions both must have form" (Hurst du Prey 1977, 1054). I almost invariably begin with the play's "inner form," its dynamics.

\subsection{Inner Form: Dynamic}

Chekhov's understanding of form is grounded in the experience of movement, as his memory of a meditation exercise taken from Rudolf Steiner's Knowledge of the Higher Worlds, And Its Attainment demonstrates: ${ }^{8}$

I searched for harmonious compositions in space and gradually came to the experience of movement, invisible to the external eye, that was present in all phenomena in the world. There even seemed to me to be such movement in motionless, solidified forms. It was movement that had created form and still maintained it [ ... ] I called this invisible movement, this play of forces, 'gesture' [ ... W When I then performed 'gestures' that I myself had created, they invariably called forth feelings and impulses of the will inside me and gave rise to creative images. (Chekhov et al. 2005, 187-188)

Chekhov has become widely known for his technique of Psychological Gesture (Chekhov 2002, 63-76, 183-215); but in practice, he worked 
with gesture much more variously than this: to define atmospheres and whole plays, for instance, as well as characters and their objectives. In the later stages of rehearsal I use gesture much more freely; but to begin with, I tend to use it to define actions and the "play of forces" in each scene, so as to avoid confusion.

I begin with a sketch of a scene that focuses on the moments of change, which I call "events", that are interspersed with what I call (after Stanislavsky) "bits" of action. Following this method, here is a sketch of Hamlet 3.4:

\section{Polonius and Gertrude come in}

Polonius instructs Gertrude and she reassures him

\section{Polonius hides and Hamlet comes in}

Gertrude condemns Hamlet's behavior and he remonstrates with her

3. Hamlet attempts to force Gertrude to sit

Hamlet tries to make his mother listen to him, Gertrude calls for help and the call is taken up by Polonius

\section{Hamlet hears someone shouting behind the arras and stabs him, Polonius dies \\ Hamlet justifies himself and accuses his mother, Gertrude protests her innocence}

5. The Ghost appears, repeats his instruction to Hamlet not to punish his Mother but to revenge his death and leaves

Gertrude tries to discover whether or not Hamlet is sane and trustworthy and Hamlet tries to persuade his mother to keep away from Claudius and keep their conversation secret

6. Gertrude promises that she will not reveal to anyone what Hamlet has told her

Hamlet and Gertrude say good night and repeat their promises to each other

7. Hamlet leaves, taking the body of Polonius with him

Gertrude composes herself

\section{Claudius comes in}

The events in bold are the first that we identified in rehearsal as they are marked by unequivocal stage directions: entrances, exits and the death of Polonius. They provided a structure for initial improvisations of the scene alternated with readings of the text, which gradually revealed the events numbered 3 and 6. Event 6 emerged from the realization that Hamlet would not leave until Gertrude had promised to keep what he had said secret. In the case of event 3, we saw that until Hamlet grabbed Gertrude she had no reason to call out and make Polonius reveal his presence to initiate the event of his murder. Likewise, Hamlet needed to be threat- 
ened and/or exasperated by Gertrude ("Nay, then, I'll set those to you that can speak" (3.4.17)) to make him grab her. Thus the action of the scene is gradually developed as a sequence of inter-related causes and effects.

I approach such a sequence or 'play of forces' by using Chekhov's suggestions for working with objectives, which he contrasted with Stanislavsky's psychological attitude:

When Stanislavsky gave his objective to his actors, we took it with our intellect, with our brain, with our thinking abilities [ ... ]. The method of taking the objective, in our sense, is first of all to imagine that you are doing this $[\ldots]$ try to appeal to your will, and inside try already to do this. Fill your whole being with the action $[\ldots]$. This is the right approach to the objective. (Hurst du Prey 1977, 905)

Therefore, while reading the scene, I ask the actors to express their objectives with gestures of their whole body. Figs. 1 and 2 show such gestures at a later stage of rehearsal. ${ }^{9}$ In fig. 1, Gertrude is confronting Hamlet after the death of Polonius: "O me, what hast thou done?" (3.4.24). Gertrude's gesture expands suddenly towards her son (though its confrontation is being deliberately undermined by the two actresses playing Hamlet, who are circling her so that she cannot keep both simultaneously in view). In fig. 2, Gertrude contracts downwards in the face of the rising, assertive gesture of Claudius' interrogation of her. When she tells him that Hamlet has killed Polonius, his gesture will change to falling: "O heavy deed! / It had been so with us had we been there" (4.1.11-12).

Thus, the initial sketch is evolved into a score of actions notated as gestures defined by the direction and quality of their movement. There are six archetypal directions in Chekhov's technique: upwards, downwards, forwards, backwards, expansion and contraction, and the interplay of those forces creates the dynamic tension of a scene. In the case of the closet scene, we found that the initial confrontational tension between Hamlet and Gertrude was best achieved by giving them both rising gestures that moved towards each other. Later in the scene we found a more harmonious dynamic as Gertrude allows Hamlet to speak by giving her a gesture of taking in what he says with a downwards, yielding movement against his dominant gesture of giving and rising, so that the dynamic of the scene flows naturally from him to her. This direction was reversed at event 6, when Gertrude gives Hamlet her word and he accepts it.

The relationship between the idiomatic expression of intention (she gives her word) and the direction of the gesture that accompanies it supports Chekhov's assertion that "what we consider a purely psychologi- 


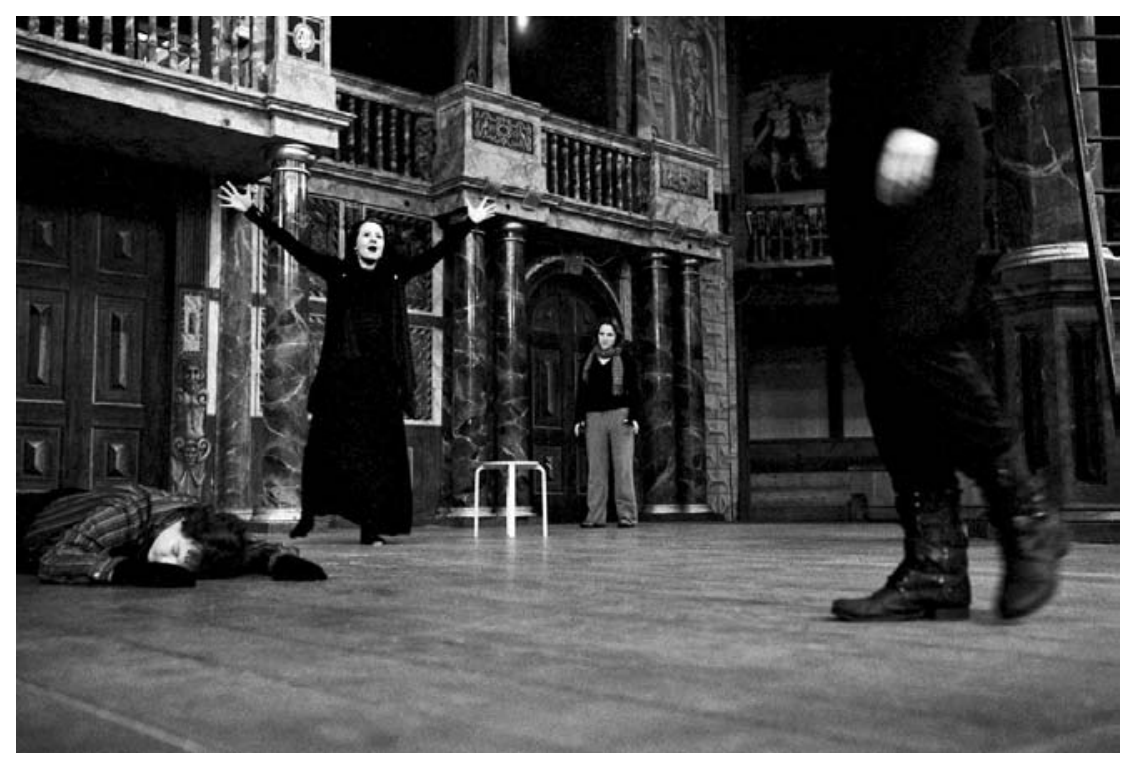

Fig. 1. Kevin Leask (Polonius), Charlotte Purser (Gertrude), Rose McPhilemy and Charlotte Hanson (Hamlets), rehearsing with gestures, Shakespeare's Globe 2011. Photograph (C) Damian Chrobak.

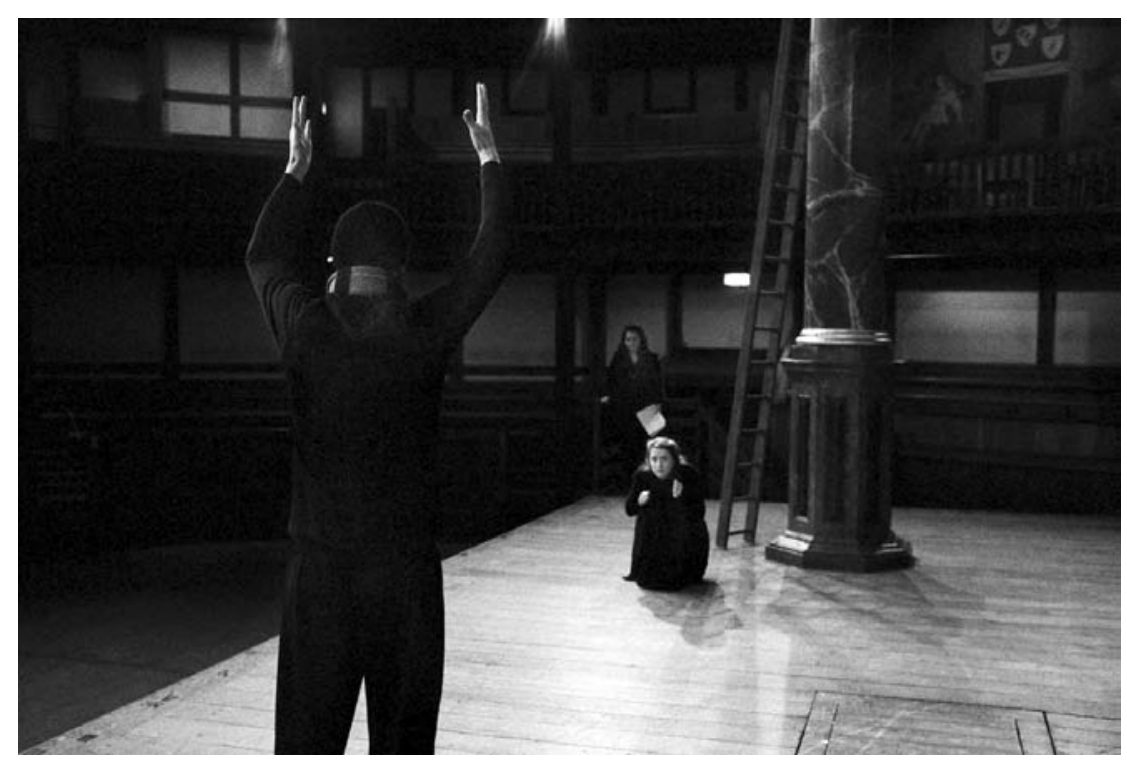

Fig. 2. David Pica (Claudius) and Charlotte Purser (Gertrude), rehearsing with gestures, watched by director Deborah Hannan, Shakespeare's Globe 2011. Photograph (C) Damian Chrobak. 
cal state of mind [ . . ] is actually described in our human language as gesture" (Chekhov and Hurst du Prey 1992, 107), an observation that underpins the more recent work of linguist George Lakoff and philosopher Mark Johnson on the ways in which conceptual understanding is grounded in perceptual experience. ${ }^{10}$ However, despite the fact that the gestures for the closet scene were chosen because they were felt instinctively to be right, Chekhov's technique can equally be applied to generate multiple versions of a scene, to explore counter-intuitive options, or even to develop a staging that feels deliberately wrong. Thus we do not have to share Chekhov's assumption that it is desirable organically to develop a performance with the feeling of truth in order to profit from his approach. We might use Chekhov's methodology to develop a staging much closer to the ideological perspective of Brecht than these examples suggest.

Once the directions of gestures for characters' actions are agreed, they provide the framework for the physical form of a scene, but it is important to emphasize the flexibility of this framework. While I insist that the direction of gestures is agreed upon, I also encourage actors to change their quality. There are four archetypal qualities of movement for Chekhov, which define how a movement is performed. ${ }^{11}$ Each movement can be molded (as if forcing its way through earth), can flow (as if supported by water), can fly (as if moving through air, almost without resistance), or it can radiate (sending out heat and light like a fire). These archetypal qualities can of course be blended to give any quality of movement we choose: moving like pouring concrete, for instance, or fizzy water, or a spluttering flame.

Changes of quality were particularly useful for the two Hamlet actors (see fig. 1). They both always used the same direction of gesture for their actions to ensure that each scene's dynamic would be clear, but looked continually for contrasts in the quality of those gestures. If one was using deliberate, molding movements, the other would respond with, for instance, the quality of flying. They could even do this in a single line: "[molding] Now, mother, / [flying] what's the matter?" (3.4.8), and this observation demonstrates the transition from the inner form of a scene's dynamics to the outer form of its articulation.

\subsection{Outer Form: Text}

In Chekhov's approach, text is treated in the same way as action, by finding its gestures. The opening soliloquy of Richard III is a helpful illustration, which I use frequently. Its first part is expansive, growing in waves from a single temporal premise ("now is the winter $[\ldots]$ made 
summer" (1.1.1-2)): "now [ . . ] now [ . . ] now [ . . ] now [ . . ]." This part is concluded by a clear transition ("But I, that am not shaped for sportive tricks" (1.1.10-14)) into the second section in which a subject: "I" becomes the focus ("I that am rudely stamped [ ... ] I that am curtailed" (1.1.16-18)). This section has an upward gesture as Richard, the play's hero, asserts his individuality. Then the final section, in which Richard, the play's villain, recounts the "plots" he has "laid" (1.1.32), which seems to me to have a taking gesture: he is taking the audience into his confidence and he is going to take everyone for a ride. ${ }^{12}$

This exercise of finding gestures for linguistic utterances, like that of developing gestures for psychological action, prevents the content of the play from becoming trapped in the world of thought. For intellectual, emotional or psychological content to be communicable on stage, both between actors and to an audience, it must take psychophysical form in a performing body. Gesture enables this process by acting as a bridge between the abstract and conceptual realm of ideas and the concrete and physical realm of performance, but it is not the only such bridge in Chekhov's technique.

\subsection{The Inner Form of a Character: The Imaginary Center}

Gestures for speech and action do not only have direction and quality, they have an origin, which relates to the form of the character. For Chekhov, the human being had three archetypal means of relating to the world:

We know that human beings have ideas, thoughts, and that we also have our feelings and emotions, which are quite different from what we call thought or ideas, and we also have our will impulses. Three different regions which can be separated one from the other -1 ) ideas 2) feelings

3) will impulses. (Chekhov and Hurst du Prey 1992, 28)

Thus we have distinct areas within the body from which actions may originate: the head (thought), the arms and chest (feelings) and the hips, legs and feet (will). Any task, or objective, is changed considerably by being undertaken through the mind, the feelings or the will.

Usually, characters have a center towards which they tend to gravitate, though this may change as they travel through the play. Working on King Lear, we identified clear shifts in Lear's center in each of the play's three phases. He began dominated by his will (banishing Cordelia, cursing Goneril), then shifted with the onset of the storm and his madness into the realm of thought, and moved finally, when reunited with Cordelia, into feeling. Locating the center in one of these areas is, however, only 
the first stage: we can subsequently explore its movements and qualities (Chekhov 2002 80-82, 138-139). Sometimes the nature of the imaginary center will be suggested directly by the text. Lucianus, the playermurderer in Hamlet, has "thoughts black" (3.2.234), for instance. Using the center, we can convert such information (or simple observations about a character) into expressive behavior. My actors use lists of such images (drawn both from the text and their imaginations) as the basis for developing their characters using the imaginary center. ${ }^{13}$

\subsection{The Outer Form of a Character: The Imaginary Body}

I use a similar approach to defining a character's outer form with an "imaginary body." ${ }^{14}$ I ask actors to envisage their character's body outside of their own and then to step into it. Then, to enable the process of accommodating the actor's body to the characteristic movements and qualities of the imaginary body, I ask a series of questions (from: "how does it walk?" to: "how does it fall in love?"), asking the actors not to impose their own behavior upon the imaginary body but to allow it to teach them about the character's manners, conduct, comportment, thoughts and feelings. As I have already observed, this exercise can also be used to move backwards from decisions about setting or costume to discover the kinds of bodies and consciousnesses that will inhabit the sorts of clothing worn by characters.

The exercise invariably has a psychological aspect, but it does not follow that it needs to be part of a psychological approach. It is possible to create an imaginary body for a role's theatrical function (the Fool in Lear, for instance) or political position (the King) and by doing so, productions that are not concerned with depicting the humanity of the characters can nonetheless remember the humanity of their actors, and not force them into mechanical or wooden performances without inner content. Working with the qualities of the imaginary center and the imaginary body offers an approach to character that does not need to accept the ideological assumptions usually associated with character-led rehearsal.

\section{The Feeling of Ease}

The achievement of a sense of form requires the imposition of the collective will of the company upon the material of the play; but this alone will not create a performance that is genuinely live:

The given lines and the business are the firm bases upon which the actor must and can develop his improvisations. How he speaks the lines and 
how he fulfills the business are the open gates to a vast field of improvisation. (Chekhov 2002, 36)

For the performance to be living, its structured form must be balanced by the feeling of ease, which creates the necessary conditions for improvisation within its given structures. To ensure that the spontaneity and responsiveness upon which improvisation depends are sustained throughout rehearsals and performances, I use exercises that focus attention on the impulses connecting speeches to each other, inserted here in italics in an example from the exchange in King Lear that leads to Cordelia's banishment by her father: ${ }^{15}$
Lear
$[\ldots]$ what can you say to draw
A third more opulent than your sisters? Speak.
Cordelia
What can I say? Nothing my lord.
Lear Nothing? Nothing?
Cordelia Nothing? Nothing.
Lear
Cordelia
Nothing? Nothing will come of nothing. Speak again.
Speak again? Unhappy that I am, I cannot heave
My heart into my mouth. I love your majesty
According to my bond. No more nor less.
Lear
No more? How, how Cordelia? (1.1.83-92)

Having gone through the text somewhat mechanically like this to find impulses to prompt each line, I ask the actors to speak those impulses as they hear them (under their breath) as a cue for the following line (and for its gesture), with the proviso that they must ensure that they have the other person's attention so that the exercise does not simply generate cacophony. In the example above, the actors might decide that some impulses (such as Lear's "Nothing?") are already written into the text, which is a common device in Shakespeare's writing (think of Hamlet's "Seems madam?" [1.2.76]). The purpose of identifying impulses such as this is to develop the feeling that the speeches are part of a single, shared dynamic, a living process of giving and receiving between the performers which, like the tension between colors in a painting or tonalities in a piece of music, communicates to an audience.

This shared dynamic is elastic: it is flexible, but can and must not be broken. Events such as Cordelia's banishment must therefore be experienced simultaneously by all of the actors on stage so that they are clear to an audience, but they must also be real and alive-and therefore cannot be completely fixed. In this quality, they are like buses, never arriving at precisely the same time, or in the same way, but unmistakable when they 
do, and having their own momentum and rhythm. For example, in the closet scene, Hamlet's attention may be drawn somehow to the arras before Polonius cries out. In that case, we would feel the event of the murder slowly unfolding well before it happens. On another occasion, the same event could arrive suddenly at the last second. But however an event arrives, if the actors are not alert and responsive to the change it represents, it will not be a genuine event: an objective fact arising from the action that makes a definitive difference to it. Rehearsing through improvisation can thus establish and reinforce a productive tension between form and ease.

\section{The Feeling of Beauty}

Chekhov asked his students to practice performing movements: "with the beauty which rises from within you" (Chekhov 2002, 16), connecting the feeling of beauty with expansion and the quality of radiation that gives, Chekhov wrote, 'a sensation of the actual existence and significance of your inner being' (Ibid. 12). Whatever the character's body is doing, the actor's body must therefore expand and radiate, so that the life of the character is sent out to the audience: 'the actor will be able, through the power of radiation, to convey to the audience ... the contents of the scenic movement together with the actor's most intimate and individual interpretation of it' (Chekhov and Gordon 115).

Radiation is strongest in pauses which are, in Chekhov's phrase, 'spiritually awake and physically quiet' (Hurst du Prey 2004, 54): 'the strongest inner activity is a complete pause. The pause as emptiness, as a full stop, does not exist on the stage' (Chekhov 2002,118). Chekhov also connected pauses with the moments in Shakespeare's plays where communication with the audience is most direct, soliloquies:

When I produced Hamlet in Russia, I asked the actor to speak the soliloquy as if it were a pause, and it was the most beautiful thing - most convincing $[\ldots]$. The pause is the strongest moment of radiation, because when we move, half of our radiation is incorporated into the movement (Hurst du Prey 1977, 1009).

For Chekhov, a pause was therefore not an isolated moment as such, but a glimpse of the continuous stream of inner life, running through every play, which is often concealed by "outer action:"

From the Point of View of Composition and Rhythm, where everything becomes a kind of "music," where everything moves, fluctuates, interweaves, we always experience a pause on the stage. The pause disappears 
only when the outer action is complete, when everything becomes outwardly expressed. (Chekhov and Gordon 137)

Therefore, if actors are connected to each other primarily through the play's action, they are connected to the audience through the pauses. This connection also travels in two directions: by opening themselves to an audience, actors become receptive and capable of responding to their atmosphere, which can therefore interact with the performance.

This capacity of Chekhov's technique to facilitate communicationnot only between script and performance, and actors and directors, but between all of the elements within a production, as well as that production and its audience-is extraordinarily valuable. What's more, the language of these conversations is not verbal but performative, grounded in image, movement and sensation. Chekhov called it "a language of gestures:"

The actor will understand you in this new language, and will be able to follow your direction without the need of speaking intellectually. The gesture will become a language between the director and the actor. (Hurst du Prey 1977, 356-357)

Because this language applies equally to both "inner" and "outer" content, it can structure a company's approach to the entire play. The verbal and psychological approaches I sketched at the outset of this essay will always tend, by contrast, to impose a binary conception of the play's tangible and intangible content, because intangible content is non-verbal (and therefore out of the reach of a verbal approach) and tangible content is not psychological (and therefore outside the scope of a psychological approach). By enabling us to approach all of a play's content with the same language of practice, Chekhov empowers us to make our own decisions about what we prioritize within that content and its expression.

By exploring performance in its own language, Chekhov's approach continually reminds us that performance is not a means of articulating second-hand an idea that has already been defined in words, such as a directorial or critical opinion, concept or instruction. Performance is a medium capable of the development of its own ideas, and these can only be directly grasped through performance; they are inevitably diminished by an attempt to translate them into any other form. By concentrating our attention on the importance of how we work, Chekhov's technique is a means both of liberating and expanding the art of performance as well as of appreciating Shakespeare as a complete artist of the theatre. 


\section{Notes}

I would like to thank all of my students, whose work has been essential to the development of the processes recorded here, and the friends, colleagues and anonymous peer-reviewers who read and commented on this piece in draft, enabling me to articulate knowledge which had, hitherto, remained stubbornly tacit.

${ }^{1}$ See Tiffany Stern and Simon Palfrey, Shakespeare in Parts. Oxford: Oxford University Press, 2007.

${ }^{2}$ These actors were from the MA/MFA in Acting (International) at East 15, see below in the main text.

${ }^{3}$ Chekhov began formally to articulate these principles late in his life (for example in Chekhov and Powers Disc 4) but he never did so definitively.

${ }^{4}$ This is close to Stanislavsky's notion of the "super-objective" but Chekhov attributed it to Stanislavsky's partner at the Moscow Art Theatre, Vladimir Nemirovich-Danchenko (Leonard 45).

${ }^{5}$ See, for instance, Leonard 32.

${ }^{6}$ In Chekhov's classes he used colored sheets like lighting gels to associate atmosphere with color (Hurst du Prey 1977, 115), an idea based on his reading both of Rudolf Steiner and Goethe's theory of color (Chekhov and Hurst du Prey 2000, 76).

${ }^{7}$ Side-coaching is the practice of giving incremental and developmental instructions to actors during an exercise.

${ }^{8}$ For more information on the influence of Steiner on Chekhov's use of gesture, see Chekhov and Gordon 74-76 and for Steiner's description of this meditation exercise, see Steiner 46-48.

${ }^{9}$ Usually I make a distinction between the area outside the performance space, in which we read from scripts and develop these gestures, and the space of the scene in which we improvise and gestures are not performed in this way. On this occasion I made an exception because the actors were struggling to maintain the clarity of the scene's form as they moved from the rehearsal room to the stage.

${ }^{10}$ See Philosophy in the Flesh: The Embodied Mind and its Challenge to Western Thought (New York: Basic Books, 1999).

${ }^{11}$ These qualities are based upon Steiner's four elements of earth, water, air and fire (Chekhov and Gordon 45-47) and are similar but not identical to Laban's efforts.

${ }^{12}$ Chekhov illustrates this exercise with Horatio's speech to the Ghost in Hamlet (see Chekhov and Gordon 66-69 and Chekhov 2002, 200-204).

${ }^{13}$ For more on the imaginary center, see Chekhov 2002, 80-82.

${ }^{14}$ For more on the imaginary body, see Chekhov 2002, 78-80.

${ }^{15}$ Although Chekhov does use the word "impulse," my use of it is more directly indebted to Sanford Meisner, see Sanford Meisner and Dennis Longwell, Sanford Meisner On Acting (New York: Vintage Books, 1987), 72-73. 


\section{Works Cited}

Berry, Cicely. From Word to Play: A Handbook for Directors. London: Oberon, 2008.

Bogart, Anne and Tina Landau. The Viewpoints Book: A Practical Guide to Viewpoints and Composition. New York: Theatre Communications Group, 2005. Print.

Chekhov, Michael, ed. Mel Gordon. On the Technique of Acting. New York: Harper Collins, 1991. Print

Chekhov, Michael, ed. Deirdre Hurst du Prey. Lessons for the Professional Actor. New York: Performing Arts Journal Publications, 1992. Print.

Chekhov, Michael, ed. Deirdre Hurst du Prey. Lessons for Teachers of his Acting Technique. Ottawa: Dovehouse Editions, 2000. Print.

Chekhov, Michael. To The Actor. London and New York: Routledge, 2002. Print.

Chekhov, Michael, ed. Andrei Kirillov and Bella Merlin. The Path of the Actor. London and New York: Routledge, 2005. Print.

Chekhov Michael, ed. Mala Powers. On Theatre and the Art of Acting. The Working Arts Library [CD]

Hall, Peter. Exposed by the Mask: Form and Language in Drama. London: Oberon, 2000. Print.

Hurst du Prey, Deirdre (ed.). The Actor is the Theatre. Unpublished class-notes from the Chekhov Theatre Studio, 1977. Michael Chekhov Theatre Studio Deirdre Hurst du Prey Archive, Dartington Hall Trust.

—_ . "The Training Sessions of Michael Chekhov." Arts Archives: Theatre Papers, The Third Series 1981-82 (2004).

Leonard, Charles (ed.) Michael Chekhov's To The Director and Playwright. New York: Harper and Row, 1963. Print.

Steiner, Rudolf. Knowledge of the Higher Worlds: How Is It Achieved? Forest Row: Rudolf Steiner Press, 2004. Print. 